\title{
Práticas de refração, refração de uma prática: gêneros discursivos e suas leituras textuais
}

\author{
Marco Antonio Villarta-Neder \\ Universidade Federal de Lavras (UFLA), Lavras, Minas Gerais, Brasil \\ villarta.marco@del.ufla.br \\ https://orcid.org/0000-0003-3857-3720
}

DOI: http://dx.doi.org/10.21165/el.v47i2.2051

\begin{abstract}
Resumo
O presente artigo pretende discutir as refrações sofridas pelo conceito bakhtiniano de gêneros discursivos na leitura de teorias advindas do campo de estudos do texto. Esse campo é constituído majoritariamente por teorias da Linguística Textual e por aquelas que podem ser identificadas no âmbito de estudos sociointeracionais no sentido mais amplo. O objetivo é destacar como essas refrações incidem principalmente sobre as práticas socioculturais, históricas e ideológicas que se constituem na/pela produção, circulação e recepção desses gêneros. Objetiva-se, ainda, destacar a refração da concepção de sujeitos, resultando que a noção bakhtiniana, fundada, ao mesmo tempo, em uma concepção co-construída na relação de alteridade e na responsabilidade axiológica seja decorrente dessa constituição.
\end{abstract}

Palavras-chave: Círculo de Bakhtin; gêneros discursivos; gêneros textuais.

\section{Refraction practices, refraction of a practice: discoursive genres and its textual readings}

\begin{abstract}
The aim of this article is to discuss refractions that bakhtinian concept of discursive genre suffers by text studies theories. This field is formed by Textual Linguistics theories and by others ones which can be identified within sociointeractional studies at the larger sense. The aim is to point out how these refractions lay down mainly over sociocultural, historical and ideological practices that constitute/are constituted at/by the production, circulation and reception of these genres. There is a purpose, as well, to point out the refraction of people conception, what results that the bakhtinian notion, based, at the same time, in a build-together conception in the alterity relationship and in the axiological responsibility due to this constitution.
\end{abstract}

Keywords: Bakhtin Circle; discursive genres; textual genres.

\section{Introdução}

Há um percurso histórico dos conceitos gestados em um longo e descontínuo período de existência das discussões e da produção teórica do que se entende hoje por Círculo de Bakhtin. Esse termo sintetiza um conjunto de deslocamentos de Mikhail Bakhtin dentro da União Soviética entre os anos 1920 e 1940, durante os quais participou de vários grupos de discussão de temáticas igualmente variadas. Desde um grupo que discutia o poeta russo Puchkin, passando por aqueles que discutiam filosofia, literatura e - supostamente - religião. A esses grupos, tão efervescentes no espírito da cultura russa daqueles anos, costuma-se chamar de círculos. 
Não somente a produção intelectual desses círculos do próprio Bakhtin (que sobreviveu à maioria de seus colegas de círculos), mas a recepção de uma obra de muitas vozes, com partes publicadas e outras escondidas da censura stalinista, também é bastante diversa. Clark e Holquist (2008, p. 22) pontuam um dos aspectos dessa recepção:

[...] Bakhtin também foi avaliado de maneira diferente em países diferentes. As circunstâncias que acompanharam a descoberta de seu trabalho fora de sua pátria respondem por muitas dessas diferenças. Por exemplo, traduções de seus livros sobre Dostoiévski e Rabelais apareceram na França no fim dos anos 60, durante a maré montante estruturalista, de modo que o melhor entendimento de sua obra pareceu dar-se no contexto do Estruturalismo ou da semiótica.

Essa leitura a partir do estruturalismo e da semiótica custou à recepção dos conceitos bakhtinianos, inclusive, uma crítica de Jean-Paul Sartre, baseada na leitura que o filósofo francês fez de um Bakhtin como um autor situado no âmbito da semiótica e da semiologia estruturalistas francesas daquele período (anos 1970), como comenta Todorov no prefácio da edição francesa da Estética da criação verbal ${ }^{1}$.

Assim, as refrações que são analisadas aqui, neste artigo, inserem-se em um âmbito, em geral, comum a qualquer processo de leitura de um referencial teóricoepistemológico em outros contextos e, de maneira mais singular, com um processo de leitura de conceitos e discussões do Círculo de Bakhtin por outros referenciais. Isto se dá não somente pela esperada diferença das condições de recepção em qualquer contexto análogo. Nesse caso, dá-se, também, por conta do quanto o referencial bakhtiniano representa uma réplica, destoante e incômoda, muitas vezes, das tradições epistemológicas e axiológicas das teorias de linguagem prevalentes.

O conceito de refração, tirado da óptica, tem relação com o processo de representação sígnica. No livro Marxismo e Filosofia da Linguagem, quando se inicia a discussão sobre signo, consciência e ideologia, tal noção aparece:

Os signos também são objetos únicos e materiais e, como acabamos de ver, qualquer objeto da natureza, da tecnologia ou de consumo pode se tornar um signo. Neste caso, porém, ele irá adquirir uma significação que ultrapassa os limites da sua existência particular. O signo não é somente uma parte da realidade, mas também reflete e refrata uma outra realidade, sendo por isso mesmo capaz de distorcê-la, ser-lhe fiel, percebê-la de um ponto de vista específico e assim por diante. (VOLÓCHINOV, 2017, p. 93).

Para enfrentar essa discussão, este artigo pretende situar compromissos teóricos, epistemológicos e axiológicos no campo dos estudos bakhtinianos e analisar como tais compromissos são refratados por um conjunto de campos a que podemos conferir alguma unidade, caracterizando-os como uma leitura a partir das teorias fundadas no texto. Tais campos constituem outra arquitetônica acadêmica, em relação ao referencial bakhtiniano.

Uma segunda frente de discussão será a de analisar refrações que se produzem em documentos oficiais e em conceitos que incidem sobre aplicação da noção de gênero textual para o ensino. Serão discutidos os deslocamentos de sentidos produzidos pelos

\footnotetext{
${ }^{1}$ Todorov apud Bakhtin (2006, p. 10).
} 
Parâmetros Curriculares Nacionais de Língua Portuguesa para a Educação Básica, lançados pelo Ministério da Educação.

Não se trata, aqui, de entender que os conceitos bakhtinianos não possam ser relidos por outros vieses e deslocados para outras construções epistemológicas e axiológicas. A análise empreendida por este artigo pretende, como recorte, em primeiro lugar, problematizar quais as implicações dessas refrações/desses deslocamentos e, por fim, discutir as implicações de algumas instâncias teóricas e outras de políticas oficiais de Educação Básica não estabelecerem distinções explícitas entre essas noções no campo bakhtiniano e em suas releituras.

\section{A propósito da noção de gênero e de seus fundamentos}

Embora a noção de gênero discursivo venha sendo principalmente buscada no texto Gêneros do discurso, publicado no Brasil no conjunto de textos composto pelo título Estética da criação verbal, vamos buscar inicialmente o conceito em Marxismo e Filosofia da Linguagem, livro de 1929:

Cada época e cada grupo social possui o seu próprio repertório de formas discursivas da comunicação ideológica cotidiana. Cada grupo de formas homogêneas, ou seja, cada gênero discursivo cotidiano, possui seu próprio conjunto de temas. Existe uma unidade ininterrupta e orgânica entre a forma da comunicação (por exemplo, a comunicação direta e técnica do trabalho), a forma do enunciado (uma réplica curta relacionada ao trabalho) e o seu tema. Portanto, a classificação das formas do enunciado deve apoiarse na classificação das formas de comunicação discursiva. (VOLÓCHINOV, 2017, p. 109, grifo do autor).

Trazemos a discussão a partir dessa citação por conta do que entendemos serem as primeiras refrações que ocorrem na construção do conceito de gêneros textuais a partir da noção de gêneros do discurso, no Círculo de Bakhtin. Há dois aspectos importantes. O primeiro deles é que Volóchinov entende essas formas discursivas de comunicação como ideológicas e cotidianas. O segundo é que cada gênero discursivo cotidiano possui seu próprio conjunto de temas.

No campo bakhtiniano, considerar as relações ideológicas não implica somente integrar a dimensão política às demais. Implica, também, e necessariamente, pensar essa instância no modo de interação e constituição dos sujeitos: é na relação recíproca com um lugar outro, somente de onde pode se conferir acabamento (ainda que provisório), que cada sujeito se constitui.

Tal constituição ocorre no âmbito de uma relação indissociável entre a materialidade sígnica e as condições ideológicas que tornam possível a existência desse sujeito sob a organização de um grupo, com a relação dinâmica da cultura e da experiência de mundo mediada por ela:

Para que um objeto, independentemente do tipo da sua realidade, entre no horizonte social de um grupo e provoque uma reação ideológica sígnica, é necessário que ele esteja relacionado com as premissas socioeconômicas essenciais da existência desse grupo; é necessário que, de algum modo, ele toque, mesmo que parcialmente, as bases da existência material desse grupo. (VOLÓCHINOV, 2017, p. 110-111). 
Dessa maneira, o conceito de gêneros discursivos, no campo bakhtiniano, não permite considerar-se somente os elementos estruturais ou as características sígnicas de um dado texto. Nem permite que se tomem as condições de produção, circulação e recepção dos textos de um gênero sem que essa inter-relação entre o semiótico e o ideológico esteja sendo considerada.

Essa indissociabilidade das formas de organização social (com o âmbito ideológico incluso) pode ser percebida em outro trecho da discussão que Volóchinov (2017, p. 109) faz:

Como sabemos, todo signo surge entre indivíduos socialmente organizados no processo de sua interação. Portanto, as formas do signo são condicionadas, antes de tudo, tanto pela organização social desses indivíduos quanto pelas condições mais próximas da sua interação. A mudança dessas formas acarreta uma mudança do signo.

Para os autores do Círculo de Bakhtin, a constituição do sujeito é sempre intersubjetiva, é um território social, no interior do qual se constrói uma relação tanto com a exterioridade desse sujeito (pelo encontro necessário com um sujeito outro, ocupante de um lugar outro, indispensável para sua constituição), quanto com a de outras práticas sociais, em diálogo com aquelas das quais participa. Volóchinov (2017, p. 211) deixa isso bem explícito:

Desse modo, a personalidade falante, tomada por assim dizer de dentro, é inteiramente produto das inter-relações sociais. Seu território social não é apenas a expressão exterior, mas também a vivência interior. Consequentemente, todo o caminho entre a vivência interior (aquilo que é "expresso") e sua objetivação exterior (o "enunciado") percorre o território social. Já quando a vivência é atualizada em um enunciado finalizado, a sua orientação social adquire uma direção para a situação social mais próxima da fala e, acima de tudo, aos interlocutores concretos.

Pode-se comparar essa perspectiva com um autor representativo de uma leitura refrativa (e, por que não dizer, refratária) à perspectiva epistemológica e axiológica bakhtiniana, que é Jean-Paul Bronckart. Ao discutir a relação constitutiva entre o social e o psiquismo individual, esse autor afirma que:

Assim, além do fato de ser constitutiva do psiquismo especificamente humano [...], a emergência do agir comunicativo é também constitutiva do social propriamente dito. Com efeito, na medida em que os signos cristalizam as pretensões à validade designativa, se estão disponíveis para cada um dos indivíduos particulares, eles também têm, necessariamente, devido a seu estatuto de formas negociadas, que se estruturar em configurações de conhecimentos que podem ser chamadas, segundo Popper (1972/1991) e Habermas, de mundos representados. (BRONCKART, 2007, p. 33, grifo do autor).

É interessante destacar que Bronckart entende que os signos "cristalizam as pretensões à validade designativa". Contrasta de maneira importante com a concepção do Círculo de Bakhtin sobre a relação entre sujeito, consciência, signo, e os âmbitos social e ideológico. Novamente Volóchinov $(2017$, p. 111) pode ajudar nessa reflexão: 
Um tema ideológico sempre recebe uma ênfase social. É claro que todas essas ênfases sociais dos temas ideológicos penetram também na consciência individual que, como sabemos, é totalmente ideológica. É como se nesse caso elas tornassem ênfases individuais, pois a consciência individual une-se de tal modo a elas que parecem pertencer-lhe; sua origem, no entanto, encontra-se fora dela. A ênfase, por si só, é interindividual.

Ao contrário dos autores do Círculo, Bronckart aposta, via reafirmação de uma racionalidade fundante do projeto Iluminista, em alguma fixidez do signo e em uma anterioridade da possibilidade desse alicerce da razão como constitutivo da consciência do sujeito. $\mathrm{O}$ autor não descarta a movência dos signos ("[...] é através desses textos e desses signos com significações sempre moventes que se constroem os mundos representados definidores das atividades humanas." (BRONCKART, 2007, p. 35)). O ponto de refração parece ser, mesmo, uma suavização do elemento ideológico e uma indistinção entre as noções de texto e discurso: "Assim, a semiotização dá lugar ao nascimento de uma atividade que é propriamente de linguagem e que se organiza em discursos ou em textos." (Ibidem, p. 35).

$\mathrm{O}$ autor belga define texto como "toda unidade de produção verbal que veicula uma mensagem linguisticamente organizada e que tende a produzir um efeito de coerência em seu destinatário" (BRONCKART, 2007, p. 137). Entende que os textos se situam em mundos discursivos, noção que assume desenvolver a partir do conceito de formações discursivas, de Michel Foucault. Mais à frente, buscando elucidar categorias conceituais e mecanismos de análise de textos, situados em gêneros textuais, invoca, entre outros, Émile Benveniste, no texto clássico do autor francês sobre os tempos verbais em francês sob a perspectiva da enunciação. $O$ que pode ser significativo da refração teórico-epistemológica que Bronckart efetua é não levar como basilar a discussão que Benveniste faz sobre a constituição dos sujeitos, basicamente a partir da natureza dêitica dos pronomes pessoais, em outro texto clássico, que é Da subjetividade na linguagem. Nesse texto, para enfrentar e questionar a concepção de linguagem como instrumento de comunicação, Benveniste (1976, p. 285) diz que: "Não atingimos jamais o homem reduzido a si mesmo e procurando conceber a existência do outro. É um homem falando que encontramos no mundo, um homem falando com outro homem, e a linguagem ensina a própria definição do homem”.

A construção epistemológico-conceitual de Bronckart, diferentemente do referencial bakhtiniano, não se assenta nessa condição de que a natureza interindividual da constituição dos sujeitos e da linguagem é indissociável. Sua abordagem dá margem, também diferentemente da visão do Círculo, de que pode haver primeiramente a construção psíquica dentro do indivíduo, para, depois, constituir-se a interação social.

A refração mais intensa que se produz na abordagem de Bronckart em relação à do Círculo - e que costuma constituir grande parte das leituras que se fazem do referencial bakhtiniano - é um deslocamento do sentido para as formas da língua, como se essas fossem, por si sós ou prioritariamente, determinantes dos (diferentes) sentidos produzidos por diferentes gêneros.

Uma questão inicial importante é que a noção de sentido, do ponto de vista dos compromissos epistemológicos e axiológicos assumidos pelos autores do Círculo, não admite que um enunciado possa ter sentido idêntico a outro, ainda que sua forma seja a 
mesma. Para discutir essa questão, vale a pena relembrar o conceito de enunciado sob o âmbito bakhtiniano. Em Marxismo e Filosofia da Linguagem, podemos ver uma consideração crítica sobre a utilização do conceito:

O enunciado isolado, finalizado e monológico, abstraído do seu contexto discursivo e real, que não se opõe a uma possível resposta ativa, mas a uma possível compreensão de um filólogo, é a realidade última e o ponto de partida do pensamento linguístico. (VOLÓCHINOV, 2017, p. 186).

Há, nesse trecho, tanto uma crítica à noção do pensamento linguístico-filológico estabelecido, quanto uma sinalização conceitual e axiológica do conceito tal como visto pelos autores do Círculo. Por inversão, o referencial bakhtiniano acredita que o enunciado é uma unidade indissociável da interação, de uma condição de respostas ativas entre os sujeitos, sem uma finalização definitiva, e sem possibilidade de existência fora de um contexto discursivo real. Há duas publicações dentro do campo bakhtiniano no Brasil que sintetizam esse conceito. A primeira é um glossário da tradução do russo para o português. Para as tradutoras e elaboradoras do glossário:

Enunciado (viskázivanie) é um elo na cadeia da comunicação discursiva e um elemento indissociável das diversas esferas ideológicas (literária, científica etc.). O enunciado sempre responde a algo e orienta-se para uma resposta. A análise do enunciado não pode ser feita dentro dos limites da linguística do sistema: aquela tendência do pensamento linguístico que, por meio de uma abstração, isola a forma linguística do enunciado (“objetivismo abstrato"). (GRILLO; AMÉRICO, 2017, p. 357-358).

O outro texto é um glossário, publicado pelo Grupo de Estudos dos Gêneros do Discurso (GEGe). O verbete enunciado, nesse glossário, apresenta a seguinte definição:

Elemento da comunicação em relação indissociável com a vida. [Suas] três principais peculiaridades [...] como unidade real da comunicação discursiva: 1. Alternância dos sujeitos falantes; 2. Conclusibilidade; 3. Escolha de um gênero discursivo. Bakhtin afirma que "o desconhecimento da natureza do enunciado e a relação diferente com as peculiaridades das diversidades de gêneros de discurso em qualquer campo de investigação linguística redundam em formalismo e em uma abstração exagerada, deformam a historicidade da investigação, debilitam as relações da língua com a vida. (GEGE, 2013, p. 36).

Para o Círculo de Bakhtin, o enunciado não prescinde de sua materialidade sígnica, de sua forma, mas tampouco pode existir sem essa articulação com outros enunciados, considerando que, em cada um deles, terá sido produzido pelas fronteiras do lugar que ocupa no mundo, em uma temporalidade, cada sujeito que participa da interação com outros sujeitos. A conclusibilidade do enunciado não está no escopo de suas operações fonético-fonológico-morfossintático-semânticas, mas nos limites entre a tomada de posição, o ato que posiciona o sujeito em relação a outros (e em reverso, em relação a si mesmo) - postupok. Ato que constitui (n)o sujeito (em) sua responsabilidade pelo lugar e tempo únicos na existência, no ser-evento.

A leitura que se faz de que é possível se trabalhar os gêneros com unidades da língua, tais como a frase, tem sido sujeita a interpretações que refratam o conceito bakhtiniano de enunciado. Essa refração atinge, inevitavelmente, a noção bakhtiniana 
de gêneros do discurso, pois esta é caudatária da noção de enunciado nos moldes como o Círculo o entende.

Esse limiar interpretativo pode ser visto em algumas obras que discutem a contribuição bakhtiniana na (longa) discussão sobre gêneros. A tradução brasileira do livro de Bawarshi e Reiff (2013, p. 110), na nota sobre a relação entre o conceito de gêneros do discurso e enunciado pode dar ao leitor uma impressão conceitual problemática:

No âmago da visão dialógica de gênero defendida por Bakhtin (1986), está a distinção que o autor faz entre frase como "uma unidade da língua" que é gramaticalmente presa e existe isoladamente, fora de uma esfera de comunicação. A frase é uma unidade gramatical que não evoca uma reação responsiva (p. 74). O enunciado, por sua vez, é uma "unidade comunicativo-discursiva" (p. 74) inerentemente responsiva e ligada à mudança de sujeitos falantes. [...] O essencial, para Bakhtin, é que os enunciados se relacionam dialogicamente com outros enunciados. E, uma vez que constituem enunciados tipificados, os gêneros também se relacionam dialogicamente com outros gêneros.

Embora os trechos de Bakhtin citados pelos autores correspondam a discussões que o autor efetivamente realiza, corre-se o risco de induzir o leitor a entender que é possível, em um contexto bakhtiniano, tomar isoladamente as duas unidades (frase e enunciado). Para o Círculo, a questão que se coloca é em que condições uma frase pode (ou não) fazer parte de um enunciado.

Essa questão tem a ver não com os limites formais, estruturais da frase, mas com a impossibilidade de se pensar a frase como unidade que participa e que é criada por falantes em interação. Não existe língua sem sujeitos que a constituam e que se constituam por meio dela. Portanto, desse ponto de vista - bakhtiniano - não há como analisar enunciados e gêneros se as condições dessa interação entre os sujeitos não forem levadas em consideração conjuntamente com as formas da língua.

Mencionamos um pouco acima, nesse texto, a importância de se pensar a noção de sentido dentro do viés do Círculo de Bakhtin. A relação mais direta entre as formas da língua e o sentido pode ser percebida nessa consideração presente em Marxismo e Filosofia da Linguagem:

O sentido da palavra é inteiramente determinado pelo seu contexto. Na verdade, existem tantas significações para uma palavra quanto contextos de seu uso. No entanto, a palavra não perde a sua unicidade; ela, por assim dizer, não se desfaz em uma quantidade de palavras equivalente aos seus contextos de uso. Obviamente, essa integridade da palavra é garantida não apenas pela integridade de sua composição fonética, mas também pela unicidade comum a todas as suas significações. Como equilibrar a polissemia essencial da palavra com a sua unidade? Essa é a formulação grosseira e elementar do problema fundamental da significação. Esse problema pode ser solucionado apenas de modo dialético. (VOLÓCHINOV, 2017, p. 194).

Uma das questões cruciais que Volóchinov aponta nesse trecho é a impossibilidade de se pensar em uma relação meramente distributiva entre palavra e sentido: não há uma correspondência entre a quantidade e a presença de palavras e a extensão de seus contextos de uso. Contexto, aqui, pressupõe uma noção ampla, em que aspectos de modalidade, relação entre diferentes semioses, papéis interacionais e a 
necessária constituição do sujeito de um lugar externo, extralocalizados ao que ocupa no momento da enunciação: para o Círculo, esse contexto é expresso pelo conceito de esferas de atividade. Sobral (2009, p. 121) procura explicar essa noção:

[...] As esferas de atividades são "regiões" de recorte socioistórico-ideológico do mundo, lugar de relações específicas entre sujeitos, e não só em termos de linguagem. São dotadas de maior ou menor grau de estabilização a depender de seu grau de formalização, ou institucionalização, no âmbito da sociedade e da história, de acordo com as conjunturas específicas. Assim, esfera deve ser entendida como a versão bakhtiniana marxista de "instituição", ou seja, uma modalidade socioistórica relativamente estável de relacionamento entre seres humanos. A esfera vai das relações de intimidade familiar ao aparato institucional do Estado, passando por circunstâncias como as que tornam possíveis comentários casuais que desconhecidos fazem um para o outro na rua sobre diversos assuntos cotidianos.

Assim, de um ponto de vista bakhtiniano, não há sentidos sem sujeitos que interagem em práticas reciprocamente constitutivas (sociais e linguageiras), coexistindo em esferas de atividade que se constituem por essas práticas e constitutivas da identidade desses sujeitos. $\mathrm{O}$ enunciado, além disso, representa um diálogo com outros enunciados já produzidos e suscita um ato responsivo ativo, que pode ser compreensão:

Compreender um enunciado alheio significa orientar-se em relação a ele, encontrar para ele um lugar devido no contexto correspondente. Em cada palavra de um enunciado compreendido, acrescentamos como que uma camada de nossas palavras responsivas. [...] Toda compreensão é dialógica. A compreensão opõe-se ao enunciado, assim como a réplica opõe-se a outra no diálogo. A compreensão busca uma antipalavra à palavra do falante. (VOLÓCHINOV, 2017, p. 232).

A réplica que a compreensão constitui como postupok, como tomada de posição desse sujeito em relação ao lugar que ocupa no mundo e ao mundo que participa de sua constituição, enreda-se nas esferas de atividade.

Pode-se analisar as refrações das leituras do conceito de gênero do discurso por alguns aspectos. Um deles são as concepções de sujeito, língua(gem) e sentidos. Outra é a recusa teórico-epistemológica e principalmente axiológica de comungar de conceitos que advêm do marxismo. Até mesmo a base habermasiana em que Bronckart se assenta tem componentes de uma leitura marxista que possibilita a leitura de uma razão que pode ser construída com algum grau de apriorismo. Ou, dito de outra maneira: a de que, necessariamente, toda ação comunicativa seja dotada de razão.

Em contraposição a essa leitura, haveria uma ponderação de que a razão, também como ato de linguagem (entendida como postupok) é discurso, é uma construção humana, nesse entremeado da tessitura das esferas de atividade. Uma réplica a uma concepção etnocêntrica de razão. Ainda que se identifiquem algumas condições de configuração para uma atividade racional, ela não estará isenta da cultura, das visões de mundo, do conjunto de condições antropológicas e históricas dentro das quais os sujeitos que a praticam (e que também são constituídas por elas).

Bronckart vai invocar o Foucault das formações discursivas. Parece faltar-lhe um Foucault do saber-poder, dos limites tênues e categoricamente produtivos, do poder soberano, disciplinar e do biopoder. Não seria uma análise marxista. Mas abordaria 
questões dificilmente analisáveis sem um aparato conceitual que trate das relações de poder como, por exemplo, o problema da normatividade dos gêneros.

Feita essa discussão de alguns posicionamentos teórico-epistemológicos sobre a noção de gêneros (de discursivos para textuais), passaremos, na seção seguinte, a tratar das leituras do conceito de gêneros para aplicação em contexto de ensino-aprendizagem na Educação Básica.

\section{Releitura de uma releitura}

Como foi elucidado na Introdução deste artigo, não é proposta aqui invalidarmos, de maneira absoluta, releituras de conceitos do Círculo de Bakhtin. Cada releitura de um referencial aponta deslocamentos epistemológicos e axiológicos em relação aos compromissos que o referencial de onde provém os conceitos estabelece. Instaura, na releitura, outros compromissos, outras responsabilidades.

Até esse momento, procuramos apontar que uma refração que constitui diferença significativa entre ambos os referenciais é o investimento conceitual e axiológico em aspectos socioideológicos como elementos constitutivos dos gêneros, em contraposição a uma não consideração desses aspectos por parte de referenciais que releem o conceito bakhtiniano de gêneros do discurso, transformando-os em gêneros textuais.

O prosseguimento da análise proposta incide, agora, sobre propostas de aplicação desses conceitos - que representam releituras - para um contexto de ensinoaprendizagem na Educação Básica brasileira. Serão discutidos alguns trechos dos Parâmetros Curriculares Nacionais de Lingua Portuguesa para o Ensino Fundamental - PCN daqui em diante, documento oficial do Ministério da Educação para nortear uma concepção diferente de Educação Básica instaurada a partir da promulgação, em 1996, da Lei de Diretrizes da Educação Nacional - LDBEN - Lei 9394/96.

Percebe-se no texto dos PCN uma construção híbrida de gêneros discursivos constitutivos de documentos oficiais e de gêneros discursivos de manuais didáticopedagógicos, voltados para o professor da Educação Básica. Partindo-se do conceito de enunciado como um dizer que se provém de alguém e que se direciona para outro, dentro de uma situação e orientando-se para um auditório (representado na presença do interlocutor ou em sua ausência ${ }^{2}$ ), podemos analisar essa estratégia textual.

Seja por atendimento a esse auditório (professor da Educação Básica sem interesse imediato ou sem formação teórica profunda o suficiente em discussão teóricoepistemológica), seja pela situação sociopolítica-institucional de conciliar interesses e vieses divergentes nos representantes da comunidade acadêmica que colaboraram para elaboração do documento, os PCN não explicitam referências de pontos de vista de autores e teorias, nem como leitura complementar. Essa escolha enunciativa pode ser analisada a partir de vários critérios.

\footnotetext{
${ }^{2}$ De qualquer maneira, o auditório é representado. Mesmo a presença física do outro não garante o conhecimento pleno do lugar que esse outro ocupa, do ponto de vista interpretativo. Assim, o auditório é sempre uma estimativa desse possível lugar e dos possíveis sentidos que tal posição do outro produziriam.
} 
Ao não se explicitar os referenciais que sustentam a discussão, estabelece-se um efeito de segredo para o interlocutor. Seu acesso aos pressupostos do referencial adotado fica restrito, o que dificulta sua condição de instaurar uma reflexão própria sobre esses pressupostos. O limite máximo desse efeito, considerando a interação entre o sujeito institucional que elabora e publica o documento oficial, é a tutela do leitor.

Outro efeito, adjacente a este, é a acuidade dos conceitos utilizados e da aplicação destes. Mesmo para especialistas em diversos vieses teóricos específicos, criase uma dificuldade adicional de identificação desse referencial de base, principalmente se levarmos em consideração pesquisadores em formação.

O terceiro efeito que apontaremos é mais complexo e está presente nos PCN. Há uma mistura de referenciais diferentes, muitas vezes com compromissos teóricoepistemológicos divergentes, quando não antagônicos. Os riscos dessa construção enunciativa podem passar pela incompreensão, vagueza ou compreensão equivocada de conceitos. Vejamos o seguinte estrato:

Produzir linguagem significa produzir discursos. Significa dizer alguma coisa para alguém, de uma determinada forma, num determinado contexto histórico. Isso significa que as escolhas feitas ao dizer, ao produzir um discurso, não são aleatórias - ainda que possam ser inconscientes -, mas decorrentes das condições em que esse discurso é realizado. Quer dizer: quando se interage verbalmente com alguém, o discurso se organiza a partir dos conhecimentos que se acredita que o interlocutor possua sobre o assunto, do que se supõe serem suas opiniões e conviç̧ões, simpatias e antipatias, da relação de afinidade e do grau de familiaridade que se tem, da posição social e hierárquica que se ocupa em relação a ele e vice-versa.

Isso tudo pode determinar as escolhas que serão feitas com relação ao gênero no qual o discurso se realizará, à seleção de procedimentos de estruturação e, também, à seleção de recursos linguísticos. É evidente que, num processo de interlocução, isso nem sempre ocorre de forma deliberada ou de maneira a antecipar-se ao discurso propriamente. Em geral, é durante o processo de produção que essas escolhas são feitas, nem sempre (e nem todas) de maneira consciente. (Parâmetros Curriculares Nacionais. Língua Portuguesa. Educação Básica, 1999, p. 17).

O trecho acima introduz elementos contextuais para depois chegar à noção de gênero. Mas há algumas indefinições: "condições em que esse discurso é realizado" alude às "condições concretas" de Bakhtin ou a "condições de produção do discurso", da Análise do Discurso de linha francesa, especialmente a pecheutiana? A organização do discurso se dá a partir de elementos que estão caracterizando o conceito de "formações imaginárias" de vertente pecheutiana ou a arquitetônica bakhtiniana?

O trecho seguinte adentra no campo bakhtiniano, mas mistura concepção de gêneros discursivos com gêneros textuais:

Todo texto se organiza dentro de um determinado gênero. Os vários gêneros existentes, por sua vez, constituem formas relativamente estáveis de enunciados, disponíveis na cultura, caracterizados por três elementos: conteúdo temático, estilo e construção composicional. Pode-se ainda afirmar que a noção de gênero refere-se a "famílias" de textos que compartilham algumas características comuns, embora heterogêneas, como visão geral da ação à qual o texto se articula, tipo de suporte comunicativo, extensão, grau de linearidade, por exemplo, existindo em número quase ilimitado. [...] 
Os gêneros são determinados historicamente. As intenções comunicativas, como parte das condições de produção dos discursos, geram usos sociais que determinam os gêneros que darão forma aos textos. É por isso que, quando um texto começa com "era uma vez", ninguém duvida de que está diante de um conto, porque todos conhecem tal gênero. Distante da expressão "senhoras e senhores", a expectativa é ouvir um pronunciamento público ou uma apresentação de espetáculo, pois sabe-se que nesses gêneros o texto, inequivocamente, tem essa fórmula inicial. Do mesmo modo, pode-se reconhecer outros gêneros como cartas, reportagens, anúncios, poemas, etc. (Parâmetros Curriculares Nacionais. Língua Portuguesa. Educação Básica, 1999, p. 18).

No trecho acima, além de persistir a dúvida de contextualização epistemológica sobre a filiação do conceito de produção dos discursos, há uma mistura de conceito de gêneros discursivos (no primeiro bloco da citação) e de gêneros textuais (no segundo bloco). Pode-se reparar que há um privilégio da estrutura em detrimento da relação entre forma e esferas de atividade. A cláusula era uma vez pode ter surgido inicialmente em contos, mas isso, em primeiro lugar, é característica de uma determinada cultura e não de todas. De algumas épocas e não de outras. De uma língua e não de outra. Seria plausível dizer que once upon the time designa as mesmas relações de sentido que era uma vez? Ainda que sejam ambas fórmulas introdutoras de início de relato, pertencem a línguas diferentes, com nuances entre gêneros nas culturas e nas construções linguageiras de cada uma dessas línguas. O pior, no entanto, é que, desconsiderando o conjunto de condições enunciativas, há uma suposição de cristalização do sentido em uma forma (talvez como Bronckart prevê...).

É nas esferas de atividade que os sujeitos vão (re)construir, por meio das formas da língua e da linguagem, os processos de construção dos textos. E esses textos só serão enunciados, de uma perspectiva bakhtiniana, se for levado em conta esse movimento de réplicas, de cadeia de enunciados. Bakhtin diz que 'Não pode haver 'sentido em si' ele só existe para outro sentido [...] Não pode haver sentido único (um). Por isso não pode haver nem o primeiro nem o último sentido, ele [...] é um elo na cadeia de sentidos [...]" (BAKHTIN, 2011, p. 382). Se não há, da perspectiva bakhtiniana, sentido em si, a cláusula era uma vez não constrói sentidos por si só, mas em relação ao conjunto de elementos presentes nas esferas de atividades em que ocorre, nas interações entre sujeitos.

Uma objeção que o leitor pode colocar é que seria um purismo não mobilizar conjuntamente os dois conceitos (gêneros discursivos e gêneros textuais). Não se trata de purismo. Os compromissos teóricos acarretam procedimentos metodológicos. Não somente para o pesquisador, mas igualmente para o professor que está diante da aplicação do conceito. A própria aplicação é uma prática que representa uma concepção, o que contraria uma visão maniqueísta da relação teoria-prática.

Se o professor acredita que o sentido se constrói por intermédio exclusivo das formas da língua, vai procurar identificar e trabalhar os gêneros em sala de aula como um repertório de formas, cláusulas, construções textuais, escolhas lexicais e morfossintáticas.

Se, ao contrário, toma como base uma concepção de que os sentidos acontecem na interação entre sujeitos, sendo concomitantes as formas da língua e de outras linguagens e os elementos das esferas de atividade em que esses sujeitos estão situados, 
procurará refletir e incentivar seus alunos a refletir sobre as condições reais e concretas em que esses sujeitos, usando essas formas para tais outros sujeitos, produzem sentidos.

Se esse raciocínio pode parecer forçado, basta nos determos novamente em algumas reflexões teóricas sobre a noção de gêneros textuais. Uma das referências importantes nesse campo trata da impossibilidade de se pensar uma progressão entre os gêneros:

A própria diversidade dos gêneros, seu número muito grande, sua impossibilidade de sistematização impede-nos, pois, de tomá-los como unidade de base para pensarmos uma progressão. Não há eixo de continuidade que permitiria pensar a construção de capacidades, senão aquele de dominar cada vez melhor um gênero, e outro, e outro, e por meio deles, a arte de escrever em geral - o que constitui precisamente a pedagogia do coroamento descrita anteriormente. Já que, visivelmente, as progressões não podem ser construídas no nível imediato da unidade "gênero", é necessário, então, recorrermos a outras contextualizações linguísticas e psicológicas. (SCHNEUWLY, 2004, p. 49).

Caminho semelhante percorre Brandão, quando tenta justificar a necessidade da tipologização. Vale a pena associarmos a sua perspectiva àquela defendida por Schneuwly acima e discutirmos as duas conjuntamente.

Por que uma tipologização? Por que essa busca por uma classificação dos discursos em gêneros? Em primeiro lugar, parece que qualquer classificação tem por objetivo pôr uma ordem no caos. Isto é, em meio à heterogeneidade dos textos com que nos defrontamos no campo da linguagem, é necessário identificá-los, ordená-los na tentativa de melhor compreendê-los. Em segundo lugar, porque toda área do saber aspira à cientificidade. Os estudos da linguagem, sobretudo a linguística, aspiram a um status científico e para isso, buscam a objetividade, categorizando, classificando seu material de análise. (BRANDÃO, 2000, p. 20).

Tanto Schneuwly quanto Brandão tomam por pressuposto que a quantidade incomensurável de gêneros impossibilita o estabelecimento conceitual de uma progressão entre eles (no caso do primeiro autor) e exige uma tipologização, dada a quantidade e a heterogeneidade deles (no caso da segunda). É interessante notar como essa percepção de quantidade excessiva denuncia o critério puramente formal adotado por ambos.

Continua tendo validade essa percepção de inumerabilidade e de caos se os gêneros forem pensados por esferas de atividades? Obviamente, não. Não existem inumeráveis modos de construção de esferas de atividades. Os atos do cotidiano não são totalmente fortuitos. Eles partem de uma construção histórica, social, cultural e ideológica de como são instituídas as fronteiras entre os âmbitos privado e público; dentre aquelas que se situam em um âmbito privado, aquelas que constituem formas de convivência relativamente abertas, como relações de parentesco, rituais de grupos que ocupam um mesmo território (como um condomínio, um bairro, por exemplo). Nem é infinito ou inumerável o continuum identitário de esferas que abrangem o religioso, o político, o estético.

A consequência imediata desse outro olhar (a partir do conceito de gêneros discursivos) seria a necessidade da construção de um conhecimento recíproco entre diferentes grupos, identidades e instâncias de vida e produção de sentidos. Primeiramente, de um ponto de vista teórico, enquanto categorias. Em seguida, 
enquanto aplicação metodológica, certamente exigiria uma reflexão mais participativa, mais atenta aos complexos matizes da alteridade.

Não se exclui a possibilidade de estudo de processos e regularidades formais no estudo dos gêneros. Sobral (1999, p. 123) faz essa ponderação: "desde que não se pretenda estudo da totalidade discursiva". Ou seja: desde que não se tomem estruturas da língua como caixinhas que "contêm" o sentido. Desde que se mantenha a relação rica e complexa entre a forma e o conjunto de condições que constitui a interação entre os sujeitos na tessitura das esferas de atividade.

\section{À guisa de exemplificação}

Para encaminharmos essa discussão, selecionamos um gênero discursivo, que podemos chamar de receita culinária. No entanto, a receita escolhida para análise e exemplificação não será a tradicional receita escrita, manuscrita, guardada quase como herança dos antepassados, em cadernos amarelados. Vamos analisar uma receita disponibilizada por um site culinário (httpp://www.tudogostoso.com.br) em um canal, que é o YouTube.

A receita selecionada é de um Bolinho de Arroz. Interessa-nos especialmente essa receita, porque se trata de um prato comum, em princípio tradicional em várias regiões do Brasil. Normalmente é feito com sobras de arroz de dia(s) anterior(es). Enquanto gênero discursivo, se pensarmos nas práticas socioculturais e econômicas ligadas ao ato de produzir, fazer circular e receber receitas culinárias, estaremos colocando em pauta as esferas de atividades.

Uma receita culinária pressupõe uma relação enunciativa com diferentes níveis de saber: um saber-fazer constituído e organizado por parte de quem dá a receita (sabe o que fazer, como fazer e sabe ensinar a fazer) e um não-saber (ou parcial) por parte de quem acessa a receita. Como se trata de uma receita simples, muito conhecida, supõese, enquanto prática sociocultural e linguageira, que o espectador do site ou do canal YouTube tenha pouca experiência de cozinha (ou desconheça esse prato por conta de diferença de identidade regional, cultural ou geracional).

Não aparece a lista de ingredientes no vídeo exibido. O culinarista que apresenta a receita vai dizendo as quantidades (de alguns ingredientes, diz a quantidade, de outros, utiliza a expressão "um pouco de"). A progressão dos elementos do texto imagético do vídeo se dá pela fala do culinarista sincronizada com o ato de mostrar os ingredientes, com o preparo e com comentários.

Há alguns aspectos interessantes. Um dos ingredientes é o queijo parmesão. O que ocorre, no entanto, com relação ao espectador, é que não é em todas as regiões do Brasil que se acha com facilidade queijo parmesão de verdade. Na grande maioria das vendas, mercearias, mercadinhos ou super/hipermercados, há queijos que são imitações do parmesão. Queijo Parmesão é uma designação de origem. Só é produzido na cidade de Parma, na Itália. Portanto, somente em importadoras que efetivamente tragam esse queijo de lá é que ele pode ser, de fato, encontrado. Em vários locais do Brasil são utilizados outros queijos como substitutos do parmesão. Em geral, são ralados, o que pressupõe uma consistência firme que possibilite essa operação. No vídeo, essa prática 
sociocultural e econômica não é mencionada, provavelmente porque é da vivência comum, compartilhada entre o enunciador e o enunciatário.

O que importa para a nossa discussão é que os sentidos do uso, da designação, da relação metonímica de se usar como parmesão um outro queijo e manter a nomeação do queijo italiano não são fixos, não estão na imagem, ou no queijo. São construídos nesse conjunto de elementos que compõe essa esfera de atividade da produção, circulação e consumo de alimentos, dos saberes sobre eles, das práticas antropológicas de alimentação e da refeição como reunião de pessoas, seja para sobrevivência, seja por questões rituais.

Outro elemento importante é considerar essa relação assimétrica de saberes e papéis enunciativos entre o culinarista/site e o espectador. Como os sentidos dessas práticas se deslocam diante de um prato que, em princípio, todos saberiam fazer? No entanto, se o site é acessado, isso revela alguma coisa que tem a ver ou com um não saber em esferas que se constituíam por ele, ou por um diálogo entre saberes (o telespectador pode conferir se o preparo é igual ao que ele conhece/sabe fazer). A receita foi postada no canal do YouTube no dia 16 de dezembro de 2011. Até a data da consulta para este artigo, o canal acusava 1.126.003 visualizações. Se considerarmos, por arredondamento, que são praticamente 6 anos de postagem, isso resultaria em 2190 dias. Daria uma média de 514 visualizações por dia.

Finalmente, chama a atenção que o culinarista faz referência à fritura dos bolinhos em óleo, mencionando uma informação técnica, que é "fritura por imersão", mas não dá nenhuma dica sobre a temperatura do óleo. Pessoas que têm alguma experiência com cozinha, principalmente com fritura de bolinhos, sabem (mesmo que por insucesso), que a temperatura do óleo é fundamental para que não aconteçam duas situações não desejáveis: ou que os bolinhos queimem ou que eles fiquem fritos por fora e crus por dentro. Pessoas muito inexperientes poderiam, também, fritar os bolinhos menos que o necessário e a massa toda ficar crua e mole.

Se pensamos nesse gênero a partir do referencial bakhtiniano, enquanto gêneros discursivos, pelo pressuposto teórico de que o sentido não está somente nos signos de uma linguagem, seremos forçados a considerar as esferas de atividades. $\mathrm{Na}$ breve análise que empreendemos aqui, levamos em conta elementos característicos dos signos (o que foi mostrado ou não, a sequência de eventos), a característica multissemiótica do texto.

Para além disso, nos obrigamos a pensar no circuito de produção, circulação e recepção de sentidos que esse texto proporciona. Quais representações do espectador a equipe do site tem para construir o texto da receita assim. Quais deslocamentos ocorrem em relação a uma receita impressa ou manuscrita. Quais pessoas teriam conhecimento não só da existência, mas do saber-fazer o bolinho de arroz, considerando que é um prato baseado em aproveitamento de sobras, que, em princípio, é uma prática econômica, sociocultural e ritual de segmentos menos abastados da população. Poderíamos prosseguir nos perguntando até que ponto o bolinho de arroz, em algumas regiões e/ou para algumas famílias ou grupos, não constituiria uma memória familiar, um prato de reminiscência da visita à casa das tias velhas ou da avó, inserida num ritual gastronômico e afetivo, que, em alguns casos, pode ir para além da condição econômica. 
Dificilmente uma abordagem de gêneros textuais daria conta de todas essas relações. Sem se dispor a pensar a produção dos sentidos no âmbito de esferas de atividade, de uma construção intersubjetiva, muitas vezes essas questões sequer surgem no horizonte de leitura de quem se propõe a analisar o gênero e seus textos.

\section{Considerações finais}

Tivemos um duplo objetivo neste artigo. Primeiramente, pretendemos situar compromissos teóricos, epistemológicos e axiológicos no campo dos estudos bakhtinianos e analisar como tais compromissos são refratados por um conjunto de campos a que podemos conferir alguma unidade, caracterizando-os como uma leitura a partir das teorias fundadas no texto.

Em segundo lugar, procuramos identificar e discutir refrações que se produzem em documentos oficiais e em conceitos que incidem sobre aplicação da noção de gênero textual para o ensino. Foram discutidos os deslocamentos de sentidos produzidos pelos Parâmetros Curriculares Nacionais de Língua Portuguesa para a Educação Básica e feita uma breve exemplificação de análise levando em conta as esferas de atividade.

Reiteramos que é possível e aceitável que se façam leituras de referenciais. O que procuramos apontar é que, como qualquer leitura, há sempre compromissos epistemológicos e axiológicos envolvidos. Por um lado, o diálogo entre uma perspectiva de Filosofia da Linguagem, de teoria de discurso, como podemos considerar o referencial bakhtiniano, com uma área com propósitos analíticos mais estritos, como são as teorias de texto, pode ser mais operacional para empregar-se na formação de professores de Educação Básica e no trabalho que eles podem fazer com seus alunos.

Por outro lado, no entanto, esse empreendimento desloca uma reflexão analítica do referencial bakhtiniano que pode abordar uma inter-relação extremamente rica entre elementos internos à materialidade sígnica da língua(gem) e as condições socioculturais, históricas, antropológicas e ideológicas que tecem a teia de construções nas esferas de atividade.

Houve um conjunto de refrações que, como parte do próprio referencial, as entende também como um processo ideológico. Recusar analisar os elementos ideológicos, históricos e socioculturais, por parte das leituras teóricas e, por extensão, deixar de criar uma instância de intercompreensão na sala de aula entre diferentes perspectivas de leitura é emblemático de um projeto de sentido que investe na forma, em detrimento do que fazemos, como humanos, com ela, por ela e como a (re)criamos.

Tais refrações, analisadas e discutidas aqui, podem se sintetizadas como:

* Deslocamento de concepção de linguagem;

Aposta em outra concepção de subjetividade;

Deslocamento conceitual:

* Processo para produto;

Inter-relação para processo localizado;

Mútua constituição para constituição sequencial; 
* Apagamento das relações ideológicas e interculturais.

Paulo Bezerra (2016), nas notas da sua tradução revisada de Gêneros do Discurso, de Bakhtin, trata oportunamente da questão da intercompreensão:

A compreensão em Bakhtin só tem sentido como intercompreensão (entre o autor de um texto e seu leitor, seu ouvinte). Neste plano, a compreensão (intercompreensão) pode ser contraposta à explicação unidirecionada (alguém armado de sua superioridade, "explica"; alguém se submete obedientemente a essa "explicação") e à "empatia' sacrificial", à "compenetração" na intenção do autor (quando desaparece o "afastamento" do leitor, quando me fundo com a individualidade do autor e eu mesmo já não existo ou... não existe aquele "eu" que interpreta o outro e o texto do outro não interessa a ninguém, é secundário). Para Bakhtin, a "intercompreensão" subentende que o sentido de qualquer texto consiste justamente em ser ele interrogativo, responsivo, que o próprio texto vive da aspiração a mim - àquele a quem o autor se dirige imediatamente ou através dos séculos na tentativa de entendê-lo.

Contudo, também é claro que, ao responder às minhas perguntas (o próprio autor não se fez essas perguntas) e ao me fazer suas perguntas, o autor do texto muda permanentemente (junto comigo), evolui, ou melhor, evolui e aprofunda-se o seu texto. E este é um fenômeno inevitável da compreensão como intercompreensão. (BIBLER apud BEZERRA, 2016, p. 166-167, grifos do tradutor).

Talvez a questão mais crucial desse diálogo de refrações não seja uma incompatibilidade total entre uma perspectiva textual e outra discursiva. É possível considerar que a principal diferença se dá em sentidos que movimentam tradições diferentes. Geraldi (2015, p. 82), ao tratar dos limites entre as noções de texto e discurso faz uma consideração pertinente: "[...] talvez tenhamos que reconhecer nosso objeto agora a linguagem e seu funcionamento e não mais a língua e seu sistema de relações internas - faz parte de um tipo de atividade humana que não se deixa reduzir ao positivismo."

Seja na formação de professores em Cursos de Letras, seja na formação continuada de professores da Educação Básica, seja, por fim, no diálogo (tenso, sempre) entre diferentes campos do conhecimento acadêmico, podemos conceber a feitura de uma ciência outra, de uma (meta)linguística na qual caiba o humano. A diferença de compromissos axiológicos que procuramos discutir aqui incide exatamente nesse ponto. Discutir gêneros discursivos ou refratá-los em leituras que apostem nas formas como continentes do sentido é entrar nessa arena. É enfrentar que as escolhas teóricas e os fundamentos epistemológicos das áreas não são neutros.

São caminhos que percorremos e o que poderia parecer óbvio é que são percorridos por nós. São nossos pés que andam, não porque os movamos pela inércia de um devir fatalista. Caminhamos na direção de nossos olhares e de nossas concepções. Porque, na relação indissociável entre dizer e fazer, concebemos, gestamos cada palavra e cada ato. Os gêneros são o conjunto de eventos que somos uns com os outros, uns por meio dos outros, todos em relação ao mundo com o qual construímos uma unidade. 


\section{REFERÊNCIAS}

BAKHTIN, M. M. Gêneros do Discurso. Tradução do russo por Paulo Bezerra. São Paulo: Editora 34, 2015.

. Estética da criação verbal. Tradução do russo por Paulo Bezerra. 7. ed. São Paulo: Martins Fontes, 2011.

Estética da criação verbal. Tradução feita a partir do francês por Maria Ermantina Galvão: revisão da tradução Marina Appenzeller. 12. ed. São Paulo: Martins Fontes, 2006.

. Para uma filosofia do ato. São Carlos: Pedro \& João Editores, 2010.

Para uma filosofia do ato. Tradução de Carlos Alberto Faraco e Cristóvão Tezza a partir da edição norte-americana Towards a Philosophy of Act, traduzida do russo por Vadim Liapunov. 1993. Mimeo.

BAKHTIN, M. M.; VOLÓCHINOV. V. Marxismo e Filosofia da Linguagem. 12. ed. São Paulo: Hucitec, 2006.

BAWARSHI, A. S.; REIFF, M. J. Gênero: história, teoria, pesquisa, ensino. Tradução de Benedito Gomes Bezerra. São Paulo: Parábola, 2013.

BEZERRA, P. Notas. In: BAKHTIN, M. M. Os gêneros do discurso. São Paulo: Editora 34, 2016.

BRANDÃO, H. N. Gêneros do discurso na escola. Coleção ensinar e aprender com textos. v. 5. São Paulo: Cortez, 2000.

BRASIL. Secretaria de Educação Fundamental. Parâmetros curriculares nacionais: lingua portuguesa. Brasília: MEC/SEF, 1997.

BRONCKART, J. P. Atividade de linguagem, textos e discursos. Por um interacionismo sociodiscursivo. Tradução de Anna Maria Raquel Machado; Péricles Cunha. 2. ed. São Paulo: EDUC, 2007.

CLARK, K.; HOLQUIST, M. Mikhail Bakhtin. Tradução de J. Guinsburg. São Paulo: Perspectiva, 2008.

GERALDI, J. W. Ancoragens. Estudos Bakhtinianos. 2. ed. São Carlos: Pedro \& João Editores, 2015.

GRILLO, S. C.; AMÉRICO, E. V. Glossário. In: VOLOCHINOV, V. N. Marxismo e Filosofia da Linguagem: problemas fundamentais do método sociológico na ciência da linguagem. Tradução e notas de Sheila Grillo e Ekaterina Volkova Américo. São Paulo: Editora 34, 2017.

SCHNEUWLY, B.; DOLZ, J. Gêneros orais e escritos na escola. São Paulo: Mercado das Letras, 2004.

SOBRAL, A. Do dialogismo ao gênero. As bases do pensamento do Círculo de Bakhtin. Campinas: Mercado das Letras, 2009.

TUDOGOSTOSO. Página pessoal. Receitas culinárias. Disponível em $<$ https://www.youtube.com/watch?v=HK-CQx8zpgw>. Acesso em: 09 out. 2017. 
VOLOCHINOV, V. N. Marxismo e Filosofia da Linguagem: problemas fundamentais do método sociológico na ciência da linguagem. Tradução e notas de Sheila Grillo e Ekaterina Volkova Américo. São Paulo: Editora 34, 2017.

. A estrutura do enunciado. Tradução de Ana Vaz, para fins didáticos, com base na tradução francesa de Tzvetan Todorov ("La structure de l'énoncé, 1930). In: TODOROV, T. Mikhail Bakhtine: le principe dialogique. Paris: Seuil, 2005. p. 287-316.

Recebido em: 10/10/2017

Aprovado em: 21/03/2018 